\title{
Dissatisfaction with Medical and Surgical Residency Training Is Consistently Higher for Women than for Men
}

\author{
C. Jessica Dine, MD MSHP ${ }^{7,2}$, Manqing Liu, $\mathrm{MHS}^{7}$, David A. Asch, MD, MBA ${ }^{1,2}$, \\ Lisa M. Bellini, $\mathrm{MD}^{7}$, Karl Y. Bilimoria, MD, MSCl ${ }^{3}$, Sanjay V. Desai, MD ${ }^{4}$, and Judy A. Shea, \\ $P h D^{7,2}$
}

${ }^{1}$ The Department of Medicine, Perelman School of Medicine, University of Pennsylvania, Philadelphia, PA, USA; ${ }^{2}$ The Leonard Davis Institute of Health Economics, University of Pennsylvania, Philadelphia, PA, USA; ${ }^{3}$ The Department of Surgery and Center for Healthcare Studies, Feinberg School of Medicine, Chicago, IL, USA; ${ }^{4}$ The Department of Medicine, Johns Hopkins University, Baltimore, MD, USA.

J Gen Intern Med 35(1):374-6

DOI: $10.1007 / \mathrm{s} 11606-019-05334-7$

(c) Society of General Internal Medicine 2019

\section{INTRODUCTION}

In an attempt to balance service and education, there is a renewed focus on trainee work experiences and job satisfaction. Overall measures of dissatisfaction likely disguise differences across defined subgroups, particularly men and women, known to experience job satisfaction and burnout differently across professions. ${ }^{1}$ A previous study showed gender differences in satisfaction during surgical residency training. ${ }^{2}$ The objective of this study was to determine gender differences in dissatisfaction with specific aspects of the institutional environment and with trainee wellbeing during both medical and surgical residency training using data from two clinical trials which investigated the effects of removing resident shift length limitations during residency training. ${ }^{3,4}$

\section{METHODS}

Sixty three internal medicine and 117 surgical residency programs were randomly assigned to be regulated by 2011 ACGME duty hour policies or by more flexible policies that did not specify shift length limits or mandated time-off intervals between shifts. ${ }^{3,4}$ By design, parallel instruments were administered in both studies to all residents in enrolled programs at the end of each training year, including 8 identical questions eliciting resident satisfaction with their institutional environment (continuity of care, patient safety, work hours/ scheduling, handoffs/transitions of care, education, and program's duty hour regulations), and satisfaction with their own wellbeing (time for rest and overall wellbeing) on a 5-point scale from "very dissatisfied" to "very satisfied."
We included only surveys that included responses identifying gender. We dichotomized satisfaction outcomes (very dissatisfied or dissatisfied vs neutral, satisfied, or very satisfied) for consistency with the previous published trials. We calculated odds ratios (OR) and associated $95 \%$ confidence intervals (CI) using a mixed effects logistic regression model with an intercept for clustering of respondents within program and an indicator for gender as the fixed effects covariate in the model and the respondent's dichotomized response as the outcome.

\section{RESULTS}

The response rate was $99.9 \%$ for medical and $99.3 \%$ for surgical residents. A total of 6271 surveys $(96.8 \%)$ identified gender.

Women medical and surgical residents reported more dissatisfaction in all eight domains compared with men (Tables 1 and 2$)$ : continuity of care $(7.2 \%$ vs $4.9 \%$; OR $0.66,95 \% \mathrm{CI}$ $0.54-0.82)$, patient safety $(5.0 \%$ vs $3.3 \%$; OR $0.66,95 \% \mathrm{CI}$ $0.51-0.85)$, work hours and scheduling (17.8\% vs $12.4 \%$; OR $0.65,95 \%$ CI $0.56-0.75)$, quality and ease of handoffs and transitions in care $(9.4 \%$ vs $7.5 \%$; OR 0.77 , 95\% CI 0.64 0.93 ), quality of resident education ( $13.2 \%$ vs $9.7 \%$; OR 0.71 , 95\% CI 0.60-0.84), their program's duty hour regulation (8.8\% vs $6.7 \%$; OR $0.75,95 \%$ CI $0.62-0.91$ ), their time for rest $(25.3 \%$ vs $19.2 \%$; OR $0.70,95 \%$ CI $0.62-0.79)$, and their overall wellbeing $(22.0 \%$ vs $16.1 \%$; OR 0.68 , 95\% CI $0.59-$ $0.77)$.

\section{DISCUSSION}

In this national study of medical and surgical residents, women reported more dissatisfaction in all domains compared with

Published online November 11, 2019 
Table 1 Number of Women and Men either Dissatisfied or Very Dissatisfied

\begin{tabular}{|c|c|c|c|c|c|c|c|c|c|}
\hline & \multicolumn{3}{|l|}{ Overall } & \multicolumn{3}{|l|}{ Medicine } & \multicolumn{3}{|l|}{ Surgery } \\
\hline & $\begin{array}{l}\text { Women } \\
(N= \\
2710)\end{array}$ & $\begin{array}{l}\text { Men } \\
(N= \\
3561)\end{array}$ & $P$ value & $\begin{array}{l}\text { Women } \\
(N= \\
1199)\end{array}$ & $\begin{array}{l}\text { Men } \\
(N= \\
\mathbf{1 3 0 5})\end{array}$ & $P$ value & $\begin{array}{l}\text { Women } \\
(N= \\
\mathbf{1 5 1 1})\end{array}$ & $\begin{array}{l}\text { Men } \\
(N= \\
2256)\end{array}$ & $P$ value \\
\hline Continuity of care (7a) & $196(7.2)$ & $173(4.9)$ & $<0.001$ & $100(8.3)$ & $75(5.8)$ & 0.012 & $96(6.4)$ & $98(4.3)$ & 0.008 \\
\hline Patient safety (7b) & $136(5.0)$ & $119(3.3)$ & 0.001 & $64(5.3)$ & $49(3.8)$ & 0.046 & $72(4.8)$ & $70(3.1)$ & 0.013 \\
\hline $\begin{array}{l}\text { Work hours and scheduling } \\
\text { (7d) }\end{array}$ & $481(17.8)$ & 442 (12.4) & $<0.001$ & $222(18.5)$ & $173(13.3)$ & $<0.001$ & $259(17.1)$ & 269 (11.9) & $<0.001$ \\
\hline $\begin{array}{l}\text { Quality and ease of } \\
\text { handoffs and transitions } \\
\text { in care }(7 \mathrm{e})\end{array}$ & $255(9.4)$ & $267(7.5)$ & 0.005 & $86(7.2)$ & $76(5.8)$ & 0.183 & $169(11.2)$ & $191(8.5)$ & 0.007 \\
\hline $\begin{array}{l}\text { Quality of overall } \\
\text { resident education }(7 \mathrm{f})\end{array}$ & $358(13.2)$ & $347(9.7)$ & $<0.001$ & 143 (11.9) & $127(9.7)$ & 0.149 & $215(14.2)$ & $220(9.8)$ & $<0.001$ \\
\hline $\begin{array}{l}\text { Program's duty hour } \\
\text { regulations }(7 \mathrm{i})\end{array}$ & $239(8.8)$ & $239(6.7)$ & 0.003 & $126(10.5)$ & $107(8.2)$ & 0.028 & $113(7.5)$ & $132(5.9)$ & 0.060 \\
\hline Time for rest $(7 \mathrm{~g})$ & $685(25.3)$ & $683(19.2)$ & $<0.001$ & $329(27.4)$ & $258(19.8)$ & $<0.001$ & $356(23.6)$ & $425(18.8)$ & 0.001 \\
\hline Overall wellbeing (7h) & $595(22.0)$ & $573(16.1)$ & $<0.001$ & $287(23.9)$ & $222(17.0)$ & $<0.001$ & $308(20.4)$ & $351(15.6)$ & $<0.001$ \\
\hline
\end{tabular}

men. Results were consistent across medicine and surgery, and they were consistent across each of the domains measured.

These results are congruent with previous data from surgical residency. ${ }^{2,5}$ A university-wide survey at a nonmedical research university suggests that perceived institutional leadership and mentoring may influence gender differences in job satisfaction. ${ }^{6}$ In addition, male and female faculty members identified different factors that contributed to their job satisfaction. Although all faculty members rated the availability of academic resources and researchsupportive workloads as important drivers for job satisfaction, women also rated positive interactions with their immediate colleagues as critical to their job satisfaction. These types of studies suggest that there are important organizational factors such as mentoring and leadership opportunities as well as differences in professional identity that may explain the observed gender differences in job satisfaction. It may be that certain opportunities are not as readily available to or different for women (such as certain types of mentorship, sponsorship, or leadership positions) but also that women weight the same factors differently when considering their overall satisfaction with their work. We did not assess these and other potential individual factors (such as expectations outside of the work environment, family stressors, and the absence or presence of other support) that may drive gender differences.

Although the factors mediating gender difference in satisfaction with medical training are unknown, these results reveal that we must attend to these differences even as we aim to improve satisfaction for all.

Table 2 Differences in Dissatisfaction between Women and Men

\begin{tabular}{|c|c|c|c|c|c|c|}
\hline & OR* overall & $\begin{array}{l}\text { Effect } \\
\text { size }\end{array}$ & $\begin{array}{l}\mathrm{OR}^{\mathrm{q}}(95 \% \mathrm{CI}) \text { in } \\
\text { medicine }\end{array}$ & $\begin{array}{l}\text { Effect } \\
\text { size }^{\dagger \dagger}\end{array}$ & $\begin{array}{l}\text { OR }^{q}(95 \% \mathrm{CI}) \text { in } \\
\text { surgery }^{\dagger}\end{array}$ & $\begin{array}{l}\text { Effect } \\
\text { size }^{\dagger \dagger}\end{array}$ \\
\hline Continuity of care (7a) & $\begin{array}{l}0.66(0.54- \\
0.82)\end{array}$ & -0.18 & $0.67(0.49-0.92)$ & -0.15 & $0.67(0.50-0.90)$ & -0.19 \\
\hline Patient safety (7b) & $\begin{array}{l}0.66(0.51- \\
0.85)\end{array}$ & -0.21 & $0.68(0.46-0.99)$ & -0.17 & $0.65(0.46-0.91)$ & -0.23 \\
\hline Work hours and scheduling (7d) & $\begin{array}{l}0.65(0.56- \\
0.75)\end{array}$ & -0.21 & $0.66(0.53-0.82)$ & -0.17 & $0.65(0.54-0.79)$ & -0.23 \\
\hline $\begin{array}{l}\text { Quality and ease of handoffs and } \\
\text { transitions in care (7e) }\end{array}$ & $\begin{array}{l}0.77(0.64- \\
0.93)\end{array}$ & -0.15 & $0.80(0.58-1.11)$ & -0.11 & $0.74(0.59-0.92)$ & -0.19 \\
\hline Quality of overall resident education (7f) & $\begin{array}{l}0.71(0.60- \\
0.84)\end{array}$ & -0.17 & $0.82(0.63-1.07)$ & -0.10 & $0.65(0.53-0.80)$ & -0.22 \\
\hline Program's duty hour regulations ( $7 \mathrm{i}$ ) & $\begin{array}{l}0.75(0.62- \\
0.91)\end{array}$ & -0.18 & $0.73(0.55-0.97)$ & -0.15 & $0.78(0.59-1.01)$ & -0.19 \\
\hline Time for rest $(7 \mathrm{~g})$ & $\begin{array}{l}0.70(0.62- \\
0.79)\end{array}$ & -0.21 & $0.63(0.52-0.77)$ & -0.19 & $0.76(0.64-0.89)$ & -0.21 \\
\hline Overall wellbeing (7h) & $\begin{array}{l}0.68(0.59- \\
0.77)\end{array}$ & -0.23 & $0.63(0.52-0.78)$ & -0.21 & $0.72(0.60-0.85)$ & -0.23 \\
\hline
\end{tabular}

*The odds ratio and associated $95 \%$ CI were obtained from a mixed effects logistic regression model with an intercept (1 random term for clustering of respondents within program), and an indicator for gender $(1=$ men; $0=$ women $)$ as the fixed effects covariate in the model and the respondent's dichotomized response as the outcome

${ }^{"}$ The odds ratio and associated $95 \%$ CI were obtained from a mixed effects logistic regression model with an intercept (1 random term for clustering of respondents within program), an indicator for gender $(1=$ men; $0=$ women $)$, an indicator for department $(1=$ surgery; $0=$ medicine $)$, an interaction term between gender and department, and an indicator for arm $(1=$ flex; $0=$ standard $)$ as the fixed effects covariates in the model and the respondent's dichotomized response as the outcome

The odds ratio in the surgery department was obtained using the lincom command in STATA

${ }^{t \prime}$ The effect size was calculated as the difference in means between men and women (men-women) divided by a weighted standard deviation 
Corresponding Author: C. Jessica Dine, MD MSHP; The Department of Medicine, Perelman School of Medicine, University of Pennsylvania, Philadelphia, PA 19104, USA (e-mail: Jessica.dine@uphs.upenn.edu).

\section{Compliance with Ethical Standards:}

Conflict of Interest: The authors declare that they do not have a conflict of interest.

\section{REFERENCES}

1. Purvanova RK, Muros JP. Gender differences in burnout: A metaanalysis. J Vocat Behav. 2010;77:168-85.

2. Ban KA Chung JW, Matulewicz RS, Kelz RR, Shea JA, Dahlke AR, et al. Gender-Based Differences in Surgical Residents' Perceptions of Patient Safety, Continuity of Care, and Well-Being: An Analysis from the Flexibility in Duty Hour Requirements for Surgical Trainees (FIRST) Trial. J Am Coll Surg. 2017;224:126-136.
3. Desai SV, Asch DA, Bellini LM, Chaiyachati KH, Liu M, Sternberg AL et al. Education Outcomes in a Duty-Hour Flexibility Trial in Internal Medicine. N Engl J Med. 2018;378:1494-508.

4. Bilimoria KY, Chung JW, Hedges LV, Dahlke AR, Love R, Cohen ME, et al. National Cluster-Randomized Trial of Duty-Hour Flexibility in Surgical Training. N Engl J Med. 2016;374:713-27.

5. Marti KC, Lanzon J, Edwards SP, Inglehart MR. Career and Professional Satisfaction of Oral and Maxillofacial Surgery Residents, Academic Surgeons, and Private Practitioners: Does Gender Matter? J Dent Educ. 2017;81(1):75-86.

6. Bilimoria D, Perry SR, Liang X, Stoller EP, Higgins $\mathbf{P}$, Taylor C. How do female and male faculty members construct job satisfaction? The roles of perceived institutional leadership and mentoring and their mediating processes. Journal of Technology Transfer. 2006; 31(3): 355-365.

Publisher's Note Springer Nature remains neutral with regard to jurisdictional claims in published maps and institutional affiliations. 